\title{
OS DESCAMINHOS DO FEMINISMO
}

\author{
Arruzza, Cinzia; Fraser, Nancy; Bhattacharya, Tithi. Feminism for 99\%: a \\ Manifesto. Verso, 2019, 85 p.
}

Como esquecer a memorável frase de Marx, no 18 Brumário, se ela continua a nos assombrar? "A história se repete, a primeira vez como tragédia e a segunda como farsa".

Nossa intenção é avaliar "Feminismo para os 99\% - um manifesto" à luz desta máxima. A leitura desse Manifesto faz-nos cair na tentação de compará-lo ao Manifesto Comunista (1848), escrito num contexto de intensas lutas urbanas pela diminuição da jornada de trabalho e pelo voto universal para todos os homens (excluindo as mulheres). O Manifesto original preconiza a luta entre as classes, considera que a violência é a parteira da história e que desse embate surgiria uma sociedade mais justa e igualitária. No gran finale conclama: Proletários de todos os países, uni-vos!

Como é sabido, a almejada união não aconteceu. Já na década de 1920, mais precisamente em 1922, durante a Primeira Semana de Trabalho Marxista, discute-se a necessidade de reinterpretar o marxismo que já não satisfaz as necessidades do século $\mathrm{XX}$, muito além da relação entre trabalhador e burguesia no mundo industrializado. Fundada em 1924, a Escola de Frankfurt assiste a derrota dos movimentos operários e a ascensão dos fascismos na Europa. Também, amarga a desilusão com os rumos da revolução soviética e do Capitalismo de Estado, com o socialismo degenerado e com o próprio proletariado que, ao enriquecer, transformou-se numa classe sem interesse específico, perdendo a capacidade de conduzir a humanidade na direção da revolução. A Escola reformulou as teses marxistas, agora era preciso encontrar novos agentes para realizar a transformação social.

No século XXI, afirma Therborn (2012), salvo algumas exceções na América Latina - a política marxista desapareceu ou foi marginalizada, "o horizonte socialista vermelho vivo de três décadas atrás desapareceu” (2012, p.147). Resta saber, quem sucederá a classe operária na tarefa de conduzir a humanidade à nova sociedade.

Lançado em 2019, Feminismo para 99\% também nasce num contexto de manifestações, embora sem a intensidade e o poder de ruptura das Revoluções de 1848. Feminismo para 99\% foi inspirado pelas mobilizações para a Marcha Mundial nos EUA, em 2017, cujo lema "um feminismo para os 99\%", foi transposto para o título. No ano seguinte, novas mobilizações no 8 de março eclodem, pelo mundo, e às bandeiras de luta contra o feminicídio e violências contra a mulher, nos EUA, agrega-se uma pauta eleitoral. Nos EUA, as manifestações tentam conectar a luta das

Loreley Garcia

UFPB. Email: loreleygg@gmail.com 
mulheres com a luta anti-Trump, logo ampliada para o combate ao neoliberalismo e ao capital em geral.

Feminismo para 99\% dirige-se às participantes das inúmeras marchas e greves que surgiram na Polonia, Itália, Turquia, México, Espanha, Argentina, Brasil e outros países, a partir do slogan do movimento Ocuppy "para construir uma aliança entre os diversos feminismos das greves de 8 de março e das marchas contra Trump, nos Estados Unidos" (Martinez e Galindo, 2019, p.74)

Porém, ao contrário do Manifesto Comunista, Feminismo para 99\% não se dirige aos proletários do mundo, mas mira a todo e qualquer movimento anticapitalista que possa abrigar-se sob o guarda chuva do Feminismo para 99\%. Ou seja, o feminismo seria dotado de um potencial transformador capaz de englobar todos os movimentos, atuar como um estuário para o qual convergiriam todas as revoltas e lutas.

Mas a questão permanece: se na revisão do marxismo, o proletariado deixou de ser o agente transformador, quem ocupa seu papel histórico? No limite, seriam as minorias desprivilegiadas, minorias raciais, étnicas, sexuais, descolonizados, pobres do mundo, os sem-tudo. A revolta geral se daria em nome dos oprimidos, aqui se considera apenas a existência de dois blocos monolíticos: oprimidos e opressores. Para abrigar-se sob o guarda-chuva proposto pelo Feminismo para 99\%, para ser um aliado, o grupo deve estar comprometido com algum 'esquema de poder" que empodere os oprimidos.

Se a luta entre as classes havia desaparecido da retórica, ela ressurge repaginada entre opressores e oprimidos e capitaneada pelo novo feminismo na luta contra o neoliberalismo.

Na medida que seleciona os aliados, o Feminismo para 99\% aponta para um inimigo a ser derrotado: o feminismo liberal, aliado do neoliberalismo, também denominado de feminismo do $1 \%$, feminismos "de umas poucas almas privilegiadas", "feminismos das elites", "feminismos gerenciais", "feminismos lean in", composto por "femocratas que pressionam o ajuste estrutural e o microcrédito no Sul Global e as políticas profissionais de blazer que recebem honorários de seis cifras para dar conferências em Wall Street" (Feminismo para 99\%, 2019, p. 13).

Entende-se que, para as autoras, feminismo liberal ou feminismo de $1 \%$ é todo aquele que não se ajusta à luta anticapitalista. O feminismo $99 \%$ é excludente com as mulheres que não partilham da ideia que o "feminismo legítimo" teria que contemplar o conjunto das lutas de todas as minorias. Com este perfil, o Manifesto adquire contornos de um feminismo populista (MARTINEZ E GALINDO, 2019, p.75).

Ocorre que esse texto, entre outros problemas, oculta a origem 100\% liberal da luta feminista. Desde a $1^{\text {a }}$ Convenção americana dos direitos, Seneca Falls Convention, em 1848, o humanismo feminista tradicional e classicamente liberal traz uma agenda específica com demandas de direitos iguais perante a lei: sufrágio, direito à propriedade, casamento, divórcio, guarda de filhos e, mais recentemente, direito ao aborto. A chamada velha onda, concentrava-se nas reformas legais e na agenda pela igualdade. 
As feministas do século XIX, como Wollstonecraft, entre outras, fundamentaram suas demandas nos princípios iluministas de justiça individual. As atuais feministas não creem mais nos princípios que influenciaram as fundadoras e inspiraram o feminismo clássico na luta pelos direitos das mulheres, mas, na sua origem, o feminismo é um movimento de caráter liberal.

Em meados dos anos 1960, surge a ideia de "gender war". A Segunda Onda, iniciada por autoras como Frieden e Greer, estende-se até os anos 1980 e granjeou uma série de vitórias legais, na sua versão liberal de feminismo, ocupada em despertar a consciência e apontar novas possibilidades de autorrealização individual para as mulheres.

Porém, a eclosão dos movimentos antiguerra e antigoverno redireciona a luta feminista para além do Iluminismo e da filosofia liberal, em direção a uma filosofia radical e anti-establishment. Em meados da década de 1970, a fé nas agendas liberais para solução de problemas sociais tende a minguar. A teoria e o ativismo feministas sofrem influência de críticos da cultura e das instituições como Marx, Marcuse, Fanon, Sartre, já não se fala em autorrealização da mulher, mas em romper com o sistema que subordina a mulher e em engajar-se com grupos solidários nesta luta. Assim, ao transcender o liberalismo proposto por Frieden ou Greer, as feministas da Segunda Onda incorporam uma dimensão política à vida das mulheres.

Nessa época, é produzida uma vasta produção de literatura feminista sob a perspectiva sexo-gênero. Autoras como Millet, Jaggar, Nye, Young, entre outras, colocam o conjunto das relações com homens em termos políticos e pretendem uma transformação mais radical do que a proposta liberal. As coisas que eram vistas como normais ao olhar destreinado são, de fato, atos de degradação da mulher. A descrença na solução liberal clássica alia-se à convicção de que a mulher continua em "estado de sítio" e sujeita ao implacável "backlash".

Pouco se avançou na coalizão com os homens no intento de produzir uma nova cultura. Mas, o que acontece se apenas as mulheres têm consciência dos seus direitos, sem que estes sejam reconhecidos pela outra metade da humanidade? Não se concebe que haja homens feministas que possam atuar como aliados na luta? A opção do movimento foi investir na ideia de sororidade. As mulheres - sempre oprimidas e vitimizadas - precisam estar unidas contra a hostilidade dos homens que não estariam dispostos a abrir mão dos seus privilégios. Construiu-se uma retórica ressentida e raivosa que coloca os movimentos em descrédito, distorce suas prioridades e fornece munição aos críticos.

Segundo Sommers (1994), o feminismo do ressentimento que racionaliza e expressa o rancor, ancora-se em um sujeito político preso nas malhas da vitimização. Isso, politicamente, pode ser um retrocesso, como ensina Frigga Haug (1992), porque ser vítima também é uma ação. Percebe-se uma visão redutora fundamentada na dicotomia nós e eles: a vítima e o perpetrador - homem, branco, rico, explorador. Muito embora, obviamente, o agressor/explorador da mulher não se resuma a esse estereótipo, a menos que se deseje ser complacente com os menos afortunados e se justifique a violência contra a mulher como consequência das duras condições de 
exploração e miséria que provocam estresse no homem trabalhador (BENERIA,2003). É inegável que condições de trabalho desumanas produzem esgotamento mental, porém a violência contra a mulher é fenômeno estrutural que faz da mulher um alvo privilegiado das agressões não perpetradas apenas por homens brancos e ricos. Elas acontecem nos barracos da periferia e nas coberturas luxuosas, em todas as classes, raças e etnias, em sociedades capitalistas, socialistas, tribais, clânicas. Entretanto, há que se considerar que os índices de violência são extremamente desiguais nas diferentes sociedades porque quanto mais ampla e refinada for a cidadania e o conjunto de direitos da mulher, mais protegida ela estará.

Outro aspecto do Feminismo para 99\% que vale a pena destacar é a exigência do comprometimento com a defesa e apropriação das narrativas de todas as minorias para ser considerada como feminista. Quem não estiver com as 99\%, há de estar com o 1\% do feminismo liberal. Essa postura, não só exclui uma multidão de mulheres do movimento, como também oblitera os objetivos do feminismo, que se perdem entre tantos descaminhos.

É comum que o debate acadêmico alcance o grande público de forma distorcida, transfigurando e banalizando o conteúdo original, trata-se de um processo denominado de sedimentação do conhecimento. No caso do debate feminista e da teoria de gênero, isso aconteceu de forma exacerbada. Na transmissão para além dos muros da academia, houve desvios e distorções que produziram uma rejeição inusitada, provocada não apenas por desentendimentos, como também pela banalização de conceitos. O senso comum passa a ver a mulher empoderada nas cantoras rebolativas, nas 'surras de bumbum', e as exibições de corpos e da intimidade como expressões de liberdade. O que poderia ser mais alheio ao feminismo? Do outro lado do espectro político, o debate sobre a "ideologia de gênero" cria uma aura de demonologia sobre o feminismo sem qualquer fundamento na realidade com a exclusiva intenção de invalidar a teoria, a partir de pressupostos nada científicos, e difamar o movimento.

No Brasil, o feminismo ganhou um novo fôlego, em 2015, para além da Slut Walk que congregava uma parcela mais jovem. A campanha contra a tentativa de implantar uma nova lei do aborto, que restringiria ainda mais o direito ao procedimento e outras campanhas e hashtag \#meuprimeiroassedio ou Chega de Fiu Fiu, usaram a abusaram da tecnologia para divulgar as pautas através do ciberativismo, alcançando as novas gerações.

Ainda assim, inúmeras mulheres não aceitam o rótulo de feminista, algo que classificam como negativo, mesmo aquelas que manifestam apoio à igualdade de direitos e oportunidades para as mulheres, ao mesmo tempo que repudiam a violência contra mulheres e meninas. Se as bandeiras do feminismo são amplamente aceitas pela sociedade, por que o feminismo é recusado e muitas mulheres não se sentem representadas pelo movimento?

Essa rejeição não é exclusiva da sociedade brasileira. Uma pesquisa realizada pela YouGov, em 2018, coordenada por Christina Scharff, do King's College de Londres, revela que no Reino Unido, $80 \%$ das pessoas, em todas as classes, são 
favoráveis à igualdade de gênero e encaram o machismo como problema social. Desta ampla maioria, apenas $34 \%$ das mulheres se classificam como feministas. Scharff discutiu os resultados num artigo na BBC News, apontando os motivos da rejeição ao feminismo: a ideia que feminismo comprometeria a "feminilidade", a crença nos estereótipos sobre as feministas (todas são lésbicas, mal amadas, raivosas etc.) e o fato de ser um movimento "man-hating".

Conforme a pesquisa, o feminismo tem mais penetração entre as classes mais altas e educadas, nas quais o feminismo é aceito por 1 em cada 3 mulheres. Nas classes mais baixas, a proporção cai, sendo uma em cada cinco mulheres que, apesar de apoiar o princípio do feminismo, não assumem o rótulo.

O Feminismo para 99\% tenta reverter esse cenário ao atrelar o feminismo a uma pauta anticapitalista para ganhar legitimidade entre as camadas populares. Sua base é o estudo da interseccionalidade, ou a interação entre todas as identidades oprimidas. Certamente, perderia o apoio do andar de cima, mas disseminaria a agenda entre as massas. Como é sabido, nem todas as feministas apoiam as pautas da esquerda, a despeito do desprezo das autoras, há feministas liberais, centro-esquerda, centro-direita e até conservadoras, que não dão suporte as novas orientações do movimento. Perder o apoio desses grupos não preocupa o Feminismo para 99\%, já não os concebe como 'feministas raíz', mas antifeministas, inimigas, $1 \%$ das privilegiadas... O Feminismo para 99\%, na pretensão de atuar como um novo sujeito histórico promotor da transformação social, perde a capacidade de agregar, mas separa e exclui importantes segmentos que, historicamente, contribuíram para conquistas das demandas feministas, seja no âmbito político, legal ou cultural.

O Feminismo para 99\% pretende dar um norte, uma direção teórica ao conjunto dos movimentos anticapitalistas e contra o neoliberalismo capitaneados pelo feminismo, ou o que sobrou dele, agora que perdeu o foco e o objeto!

No limite, esse feminismo que junta no mesmo caldeirão todos os anticapitalistas, vai perdendo sua razão de ser- a própria mulher- quando o sexo feminino começa a se dissipar em "vários tipos de mulher". Butler (2014) já reviu posição com relação à identidade de gênero ao afirmar que desconsiderou as pessoas trans quando rejeitou a importância da identidade em suas vidas. Há que se perguntar qual o sentido da identidade de gênero ter importância para pessoas trans e não para héteros.

Há feministas que não aceitam a classificação de mulher cisgênero, ou a ideia da heterossexualidade como expressão da Síndrome de Estocolmo. Há feministas que não aceitam que o direito ao aborto tenha sido abandonado para obter apoio político de grupos religiosos, entre outras "traições" realizadas pelo feminismo populista. Essas feministas são, seguramente, bem mais que apenas 1\% e desejam novos rumos para o feminismo, perdido na crise de identidade desta, como nomeou Noretta Koertge (1995), loteria da opressão. 


\section{Referências}

BENERÍA, Lourdes (2003) Gender, development and globalization: economics as if all people mattered. New York: Routledge.

BUTLER, J. (2014) Theterfs. Entrevista concedida a Cristan Williams. Disponível em: http://theterfs.com/2014/o5/o1/judith-butler-addresses-terfs-and-the-work-ofsheila-jeffreys-and-janice-raymond/ Acesso em: abril de 2019.

GARCIA, L. (2004) "TECENDO FIOS ENTORNO DE 'BEYOND FEMALE MASOCHISM': uma visita às idéias de Frigga Haug”. CAOS. n. 6. Dossiê Gênero.

MARTÍNEZ, Teresa O. e GALINDO, Martha Z. (2019) "Leitura crítica de um manifesto feminista populista”. Revista USP, n. 122: Dossiê Feminismos.

MARX, Karl. (2006) O Dezoito Brumário de Louis Bonaparte. São Paulo: Centauro.

MARX, Karl e ENGELS, Friedrich (1998) Manifesto do Partido Comunista. Estudos Avançados, 12(34), 7-46.

PATHAI, Daphne e KOERTGE, Noretta ( 2003) Professing Feminism: Education and Indoctrination in Women's Studies. Lamhan \& Plymouth: Lexington Books.

SCHARFF, Christina, Por que tantas mulheres jovens não se identificam como feministas? BBC News, Brasil. https://www.bbc.com/portuguese/geral-47283014. Acesso: março de 2020.

SOMMERS, Christina H. ( 1994) Who Stole the Feminism? How women betrayed women. New York: Simon \& Schuster.

THERBORN, G. (2012). Do marxismo ao pós-marxismo? Tradução Rodrigo Nobile. São Paulo: Boitempo, 2012.

Recebido em 10/03/2020.

Aceito: 20/05/2020. 